\title{
Between language frames: seriality and variation in computer-coded film. A case study with a code-generated abstract film
}

\author{
Entre cuadros de lenguajes: serialidad y variación en películas basadas en lenguajes de \\ programación. Caso de estudio con un corto generado por código \\ Luis Fernando Medina Cardona \\ Universidad Nacional de Colombia, Sede Bogotá, Colombia \\ Julián David Sandoval Ospina \\ Universidad Nacional de Colombia, Sede Bogotá, Colombia
}

\begin{abstract}
Communication consists of basic units of information transferred between emitters and receivers, often functioning inside a whole structure called language that allows the formation of an unlimited multiplicity of relationships. Conscious or tacit, communication ranges from the explanation of a complex idea, to the natural reading of body conditions that manifest that an individual is up to reproduction. That natural sense of decoding, lets us automatically recognize a certain relationship between whatever two objects we put together, like how a black object relates to a white one, or a top one to the bottom, or even one to the many, constituting a primitive sense of idea, order or thought, without even a representation of the subject. Applied to Film, those kinds of relationships between forms are rhythmic relationships, and rythm is basically the essence of filmmaking, as film (same as music) is a form of art that takes place along time and in the rendition of movement, but rather precisely in the temporal distribution of connected blocks of image/movement, timed chains of tension and release that give a certain sense of mathematical relationships settling the base for an universal language, Giving these considerations , what happens when the language of film is ranslated into a computer programming language in order to emulate cinematic properties? What tensions and nuances emerge? This paper will address these issues using an arts based research project of recreating a short abstract film using entirely the popular media arts prototyping language Processing.
\end{abstract}

Keywords: Arts Based Research, Expanded Cinema, Programming Languages, Synthetic Image, Cameraless Cinema.

\section{Introducción}

La imagen en movimiento ocupa un lugar privilegiado y con fuerte potencial artístico en el ecosistema de medios actual. Como todo lenguaje, la imagen en movimiento cuenta con la posibilidad de servir de vector comunicativo, pero, también, cuando deviene en artefacto artístico, trasciende la visión instrumental de transmitir un mensaje y puede sorprendernos, conmovernos y hacernos experimentar lo sublime. Dicha capacidad aún sigue vigente, independientemente del medio de inscripción de las dimensiones espaciales y la temporalidad que componen la imagen. Ya sea en fotogramas organizados en una línea de celuloide o en pixeles organizados en líneas de datos que, a su vez son manipuladas por líneas de código, propiedades como el ritmo de una secuencia mantienen la cohesión entre cuadros. Esta reflexión se complica cuando consideramos la abstracción, por un lado, en una imagen abstracta separada de referentes concretos $y$, por otro lado, cuando esta es representada en una tecnología llena de abstracciones, como la imagen digital y el software. Ante ello, surgen varias preguntas como ¿qué cualidades culturales transversales permanecen en la imagen en movimiento cuando es representada por símbolos abstractos digitales?, ¿cómo mantener propiedades, como el ritmo, cuándo las imágenes son generadas por símbolos como las líneas de programación?

Con el fin de abordar estas preguntas surge "Ritmo 2021". Es un proyecto de investigación-creación de la Facultad de Artes de la Universidad Nacional de Colombia (Bogotá), cuyo objetivo es producir un corto experimental abstracto usando exclusivamente un lenguaje de programación, en este caso, Processing. De esta manera, el corto producido iría más allá de la imagen sintética y simulada (Machado, 2007, 101-109), generada por computador, y permitiría analizar el audiovisual moderno, ya que la programación y el código nos permite comprender mejor nuestros sistemas culturales actuales (Montfort 2016, 273). De manera complementaria, el programar un corto, en lugar de rodarlo, pone de manifiesto una relación más estrecha con los mecanismos algorítmicos circundantes y libera a los programas de software de la concepción de herramienta meramente instrumental. En otras palabras, la imagen sintética lleva años con nosotros siendo manipulada por programas de animación, modelado y edición de los cuales desconocemos su código interno. Por el contrario, el generar la imagen en movimiento directamente con instrucciones de programación elimina niveles de mediación y brinda un mayor control sobre el resultado, sobre todo tratándose de imágenes abstractas.

Para ilustrar la afirmación anterior, hay que pensar en el nombre dado al proyecto: "Ritmo 2021". Este hace referencia al corto experimental Rhythmus 21 (Richter 1921), concebido en pleno auge de las vanguardias de inicios del siglo $x x$ y en el cual se inspiró inicialmente la propuesta. La selección de este punto de partida obedeció a dos motivos: uno histórico y otro estético. En primer lugar, porque es un homenaje del centenario de esta pieza seminal, catalogada como uno de los primeros ejemplos de cine abstracto $y$, en 
segundo lugar, porque sus formas recuerdan primitivas básicas comúnmente usadas en Processing, donde se destacan el rectángulo, cuadrados y círculos. Esta combinación constituye la base de la hipótesis de trabajo tanto de la pieza a desarrollar como de este texto. La materialidad de algunas películas abstractas pioneras, visible en el método de trabajo de operar directamente sobre el celuloide sin una cámara, cuenta con un equivalente moderno en el acto de generar visuales directamente mediante códigos de programación sin recurrir a una realidad tangible para retratar. Esto implica que las formas abstractas no están separadas de la materialidad de un medio, sea analógico y digital, y que dicha relación compone un acto creativo y sensorial.

Para discutir los elementos descritos, este texto está estructurado de la siguiente manera. Las tres secciones siguientes se titulan respectivamente "Del tiempo: impacto, imagen y distancia recorrida", "Del signo: lo simbólico concreto y lo simbólico abstracto“ y "Del ritmo y la armonía: el vínculo". En un tono personal, se establecen los ejes de esta propuesta con temas que vinculan la vivencia de una imagen con lo simbólico y el ritmo visual. Posteriormente, una sección resumirá el recorrido de la abstracciones fílmicas a las de código, con el fin de comprender mejor el marco teórico de la propuesta. Luego hay una sección específica para el proyecto Ritmo 2021, en el cual se describirá con brevedad la programación estética, la metodología y obstáculos en la programación del primer prototipo audiovisual. Finalmente, las conclusiones postulan reflexiones estéticas y teóricas del proyecto y plantean la promesa de la colaboración abierta como una obra relacionada.

\section{Del tiempo: impacto, imagen y distancia recorrida}

Si miramos la obra de arte como un dispositivo de espacio-tiempo donde sucede el arte, es decir, uno en el que un espectador dado experimenta el arte en el momento en el cual se encuentra con la obra, estaríamos abordando el concepto del arte de una manera similar a la que pensaríamos en cualquier conjunto de comunicación emisor-mensaje-receptor. Se trata de un circuito de información que despliega una experiencia temporal al encontrarse completo en estos tres elementos. Al pensar en esta experiencia como cualquier otro conjunto semántico, encontramos que, junto con esta condición, la obra de arte adquiere también unos problemas comunes de representación. Lo simbólico solamente tiene un valor para quien pueda descifrarlo, y también existe un breve momento de transferencia de información que se constituye como un choque entre el receptor y el contenido de la obra. Vemos entonces al arte como experiencia en el tiempo, el sujeto se encuentra con la obra en un momento determinado y experimenta el arte. Como explicaba Heidegger (2003, 29), "El tiempo es aquello en lo que se producen acontecimientos" y la imagen es la resolución semántica de la experiencia del arte.
De esta manera, cuando experimentamos una obra de arte, el impacto de la imagen se resuelve en nosotros en un lugar diferente de los ojos; si la imagen nos toca, desata su potencia, nos impacta, aunque cerremos los ojos. En ese impacto se encuentran el momento presente y la memoria, los tejidos del pasado se agitan en el presente y esculpen inevitablemente el porvenir. Pero, en este despliegue semántico visto como experiencia temporal, es necesario distinguir también las especificidades del flujo del tiempo. De forma más precisa, hay que separar las imágenes en dos grupos: las imágenes estáticas y las imágenes dinámicas, o bloques de imagen/movimiento. Cuando una imagen estática impacta, resuelve toda su potencia en un solo momento, una corta explosión de energía se dispara en un lapso corto de tiempo (burst), y dispara en el espectador un remanente de movimiento interno, como un sonido transiente seguido de una reverberación, o una perturbación momentánea en el agua causada por una piedra que cae y suscita un movimiento ondulatorio. Aunque este movimiento remanente tenga una duración prolongada y, aunque - por ejemplose pueda observar una pintura con detenimiento en el detalle, la imagen desata la mayor parte de su potencia en el momento del choque. Así mismo, están las imágenes dinámicas, las cuales, a diferencia de las imágenes estáticas, ocupan una distribución alargada del tiempo y despliegan su potencia de una manera igualmente dilatada. Podría pensarse en esta delación como la proyección de un cuerpo en su eje de tiempo o trayectoria. Algo similar al concepto de geometría del tiempo de Einstein-Grossman o "space time continuum" en el que, dada la característica que tienen los elementos para existir en más de un solo momento, se ubican en el espacio con unas coordenadas $X, Y$, $Z$ (espaciales), y también necesitan una coordenada temporal, pues los objetos cambian de posición a través del tiempo,

The views of space and time which I wish to lay before you have sprung from the soil of experimental physics, and therein lies their strength. They are radical. henceforth, space by itself, and time by itself, are doomed to fade away into mere shadows, and only a kind of union of the two will preserve an independent reality. (Minkowski 1976, 339)

Thus the physical description was four-dimensional right from the beginning. But this four-dimensional continuum seemed to resolve itself into the three-dimensional continuum of space and the one-dimensional continuum of time. This apparent resolution owed its origin to the illusion that the meaning of the concept "simultaneity" is self-evident, and this illusion arises from the fact that we receive news of near events almost instantaneously owing to the agency of light. (Einstein 2014)

Así que, si tomamos el movimiento físico de un cuerpo y rastreamos su trayectoria hacia el pasado, podemos obtener una imagen de la distancia recorrida por ese cuerpo. Como lo que sucede con las fotografías de larga exposición. Para percibir una imagen estática, bastaría con conocer su posición $\mathrm{X}$, 
Y, Z, y un fragmento de su posición temporal, pero, para percibir una imagen dinámica, es necesario recorrer esa posición temporal con el objeto. De esta forma, aunque fuera teóricamente posible obtener en un momento dado una fotografía de larga exposición que contiene en una imagen estática, la distancia recorrida por un cuerpo, esta imagen sería incompleta o diferente de la imagen dinámica, pues la imagen dinámica debe recorrer la trayectoria junto con el objeto y acompañarlo dilatándose en el tiempo. Teóricamente, podríamos comprimir una película entera en un fragmento de un segundo, pero esta compresión será siempre incompleta, carente de carga semántica $\mathrm{o}$, al menos, completamente resignificada. Así, entonces, si las imágenes estáticas son como percusiones transientes que dejan una reverberación en el espectador, las imágenes dinámicas son de la naturaleza de la reverberación misma, más parecidas a las notas pedales que mantienen una intensidad constante con el flujo del tiempo y que se resuelven paulatinamente en un cuerpo exactamente en la misma medida en que el tiempo avanza.

El proceso de resolverse en un cuerpo se le conoce, según las apreciaciones de Pierre Levy, como actualización (cercano a la materialización, pero no necesariamente material). Se trata del encuentro entre lo virtual, o lo que potencialmente es, y lo actual, o lo que en efecto es. Para el caso de las pinturas, las fotografías o los dibujos, esta actualización sucede rápidamente, condensa todo lo que potencialmente es y desata esa potencia en un solo choque con el espectador.

La palabra virtual procede del latín medieval virtualis que, a su vez, deriva de virtus: 'fuerza', 'potencia'. En la filosofía escolástica, lo virtual es aquello que existe en potencia, pero no en acto. Lo virtual tiende a actualizarse, aunque no se concretiza de un modo efectivo o formal. El árbol está virtualmente presente en la semilla. Con todo rigor filosófico, lo virtual no se opone a lo real sino a lo actual: virtualidad y actualidad solo son dos maneras de ser diferentes.

A diferencia de lo posible, estático y ya constituido, lo virtual viene a ser el conjunto problemático, el nudo de tendencias o de fuerzas que acompaña a una situación, un acontecimiento, un objeto o cualquier entidad y que reclama un proceso de resolución: la actualización. (Lévy 1999, 10-11)

El sonido, la música, el cine o cualquiera de las artes del tiempo pertenecen a las imágenes dinámicas, se componen de una distancia recorrida y solo pueden actualizarse recorriendo esa distancia (en el tiempo). Permiten que el espectador experimente la obra, no como hecho estático, o pico transiente, sino como un momento que se continua en el siguiente y luego en el siguiente. Estas imágenes, aún si no son visuales, resuelven su potencia en nosotros cuando experimentamos el tiempo junto con la obra. Experimentamos un momento progresivo y encontramos también en el tiempo algo que nos experimenta. Nuevamente, al igual que las imágenes estáticas, si una imagen nos toca, su impacto se resuelve también en un lugar diferente de los ojos. Encuentra nuestras heridas abiertas, pero, esta vez, la perturbación de la piedra en el agua es continua y de gran escala, como una ola. Este movimiento puede detenerse cuando cerramos los ojos (o los oídos) y se reanuda cuando los volvemos a abrir, los tejidos del pasado de nuevo se agitan en el presente, pero esta vez no esculpen las bases del porvenir, sino que resuelven la tensión entre la potencia y el acto, se convierten en el porvenir mismo.

\section{Del signo: lo simbólico concreto y lo simbólico abstracto}

En este apartado volvemos a los problemas de representación que puede tener la obra de arte al ser vista como dispositivo espaciotemporal. Decíamos que las imágenes pertenecen al dominio de los símbolos y que lo simbólico solamente tiene un valor para quien pueda descifrarlo. Según el modelo Shannon-Weaver, la comunicación consiste en la transferencia de unidades básicas de información entre emisores y receptores que, a menudo, funciona dentro de una estructura compleja, a la que llamamos lenguaje, la cual permite la formación de una ilimitada multiplicidad de relaciones.

Language is a process of free creation; its laws and principles are fixed, but the manner in which the principles of generation are used is free and infinitely varied. Even the interpretation and use of words involves a process of free creation.

(Chomsky 2008, 87-88)

Decíamos también que, teóricamente, podríamos comprimir una película entera en un fragmento de un segundo, pero que esta compresión será siempre incompleta. Algo similar sucede por ejemplo con una cámara lenta: aun cuando pudiéramos percibir la parte simbólica concreta de la carga semántica al ver una escena de cámara lenta acelerada a la velocidad normal, se perdería cierto metatexto. En concreto, una acción determinada llevada a cabo por un personaje comunica regularmente, para el caso del cine, la historia que se desarrolla y es fundamental. Pero hay otra parte de la potencia del arte que solamente será liberada si percibimos la escena en cámara lenta, seguramente como la decidió el director y que conserva en ellos una intención estética, fuera del dominio de la razón.

Cuando encontramos un elemento simbólico concreto, la manera en que lo desciframos está completamente distorsionada por nuestra experiencia concreta, nuestra cultura, nuestra edad y lo que podría estar adjunto a ese símbolo producto de experiencias anteriores. Sin embargo, una decisión estética, del tipo cámara lenta, encuentra más fácilmente un valor ajeno a lo concreto de nuestra propia experiencia. Podría más fácilmente ser transversal a la cultura y estaría más cercano a algo como el lenguaje universal. Este tipo de elementos de naturaleza racional secundaria es lo que podría llamarse simbólico abstracto. 
El tono, el ritmo, la velocidad y el gesto hacen parte de este dominio y son, por ejemplo, elementos que no son ajenos a estados más borrosos de la percepción, como el trance o la ensoñación. También podemos encontrar las raíces de estas apreciaciones en circunstancias más primitivas de supervivencia; es apenas natural que estemos programados evolutivamente para apreciar algunos elementos de manera tácita, como los colores de una fruta en mejor estado o las señales corporales que indican que un individuo determinado se encuentra en un estado apto para la reproducción. Esto nos predispone a reaccionar de manera distinta ante ambientes calurosos o fríos, en situaciones de luminosidad o penumbra y, por extensión, también obtenemos naturalmente una lectura tácita de un objeto grande frente a uno pequeño, dos iguales puestos de manera simétrica o dos iguales de distinto color. Estas percepciones establecen un marco natural de sensibilidad artística y nos hacen vulnerables de diferente manera a lo grande, pequeño, curvo, afilado, serial y rítmico.

En este punto también es fundamental la noción de autor. Hasta ahora hemos procurado entender la manera en la que el arte, como vehículo espaciotemporal, descarga su potencia en su encuentro con el espectador, sin embargo, es primordial en este esquema de comunicación el papel del emisor, el artista. Sucede que, para algunos mensajes en específico, nuestra forma habitual de comunicación concreta es en efecto funcional. Esto permite contar historias, por ejemplo, un hombre espera a su hija a la salida de un hospital. Esa es una idea concreta que necesita comunicarse con símbolos concretos: un hombre, un hospital, una hija, pero, sin los elementos súbitos de lo simbólico abstracto, la historia carecería de vida. ¿Cuál es el tamaño de la espera?, ¿cuál es la textura?, ¿cuál es el ritmo?, ¿cuál es el tono? El autor es capaz de transmitir, de esta manera, una sensación o sentimiento determinado. Esta tensión se incorporó sutilmente en su ADN y se transmitió nuevamente en el vehículo espaciotemporal del arte en la forma de escalas, velocidades, armonías, duraciones, ritmos.

\section{Del ritmo y la armonía: el vínculo}

En este dominio de lo tácito, es fundamental la noción de codificación ajena a las convenciones culturales. Se puede pensar en las reducciones de un elemento a sus condiciones estéticas, como si se tratase de un dejo de superficialidad. Eliminar lo simbólico concreto de una obra reduce su valor a condiciones estéticas subyacentes y algo similar sucede con la cultura. Podría pensarse en las expresiones artísticas abstractas como una forma de vacío conceptual que recae solamente en la forma, pero una segunda reflexión al respecto nos podría llevar a la idea de que, en lo cultural, lo estético contiene tácitamente las revelaciones de los elementos centrales de la civilización. Así, cuando una contemplación o reflexión recurrente empieza a tener un valor cultural determinado para una comunidad, se convierte en un símbolo: una palabra, un glifo o una atribución de especialidad sobre un objeto determinado, como el sol o el agua. Este símbolo encapsula efectivamente esta primera contemplación y se convierte en una herramienta de comunicación. Con los valores estéticos, estas expresiones muestran con delicadeza algunas contemplaciones recurrentes de la cultura, por ejemplo, una cultura que aprecia como valor predominante la alegría, tendrá una inclinación estética diferente de una en la que se aprecia de manera profunda la eficacia. Lo mismo ocurre en una cultura que se rige en la propiedad privada en comparación a una que transita libremente por el territorio, con el tiempo, los elementos cotidianos como una reja o una puerta, que en principio tenían el valor simbólico concreto de marcar una delimitación, empiezan a estar cargados súbitamente de valores simbólicos abstractos: tonos, velocidades y ritmos específicos. Los elementos centrales de la civilización se decantan en elementos estéticos y es así como existe una noción estética del tiempo (la época), una estética de los pueblos o una estética de los lugares. Estos detalles sutiles revelan grandes aspectos de la cultura. La estética de lo ostentoso, de lo inacabado o de lo asfixiante construyen una atmósfera que se transfiere a lo individual y, más tarde, también a lo artístico.

Con el tiempo, un determinado ritmo transmite una sensación o sentimiento, y permea profundamente en dominios más primitivos e inaccesibles a la razón que los símbolos concretos. Estas maneras de representación acuden a lo subconsciente para transmitir valores que son transversales a la experiencia humana y que no dependen de las convenciones culturales para ser descifrados. Se aproxima más certeramente a la noción de lenguaje universal. Numerosas corrientes del arte (de la cultura) se han empeñado en romper estas relaciones semánticas y en construir imágenes con sentidos más primitivos de las ideas, el orden o el pensamiento. Richter, por ejemplo, que en principio era retratista, empezó a alejarse paulatinamente de la idea de sujeto, minimizando también la noción de objeto:

Influenced by cubism and its search for structure, but not satisfied with what it offered, I found myself between 1913-1918 increasingly faced with the conflict of suppressing spontaneous expression in order to gain an objective understanding of a fundamental principle with which I could control the "heap of fragments" inherited from the cubists. Thus I gradually lost interest in the subject - in any subject - and focused instead on the positive-negative (white-black) opposition, which at least gave me a working hypothesis whereby I could organize the relationship of one part of a painting to the other. In doing so, "form," as such, became a handicap and was replaced by straight or curved divisions of the canvas, which in itself became a surface on which opposites were to be organized. Repetition of the same element on different parts of the canvas, and repetitions with minor or major variations, permitted a certain control. (Richter 1952, 79) 
Estas primeras reflexiones acudían aún al dominio de las imágenes estáticas. La síntesis formal del no sujeto le permitió a Richter acercarse a las fibras más primitivas de la condición humana; entendió que la base del sistema de comunicación es la relación y no es ninguno de los tres nodos que la forman (emisor, receptor o el mensaje). El cuerpo de la comunicación no se encuentra en ninguno de los elementos que la componen, sino en el vínculo que se establece al ponerlos juntos, aquí se encuentran representados mediante las nociones de ritmo y armonía.

Ritmo, del griego rhythmós, 'cualquier movimiento regular y recurrente', y armonía, del griego harmonía, que significa 'acuerdo, concordancia', y este del verbo ¿́ $\rho \mu \delta ́ \zeta \omega$ (hermoso) 'ajustarse, conectarse'. De manera que el ritmo y la armonía recogen las expresiones mínimas de la vinculación. La armonía simboliza de manera abstracta el vínculo entre un objeto y los le acompañan, y el ritmo recoge las relaciones de recurrencia y movimiento, la serialidad y variación. En paralelo con la visión del arte como dispositivo espaciotemporal, lo fundamental de la relación semántica no se trata entonces tampoco del artista, ni de la obra, ni del espectador, sino de la relación misma, el arte mismo. Como decíamos, el sujeto se encuentra con la obra en un momento determinado y experimenta el arte. Esta reducción de la obra a lo rítmico es una apología del vínculo, la simplificación de la relación, el rastro súbito de la condición humana desplegándose desde el vehículo espaciotemporal. Se recorre una distancia al resolver su potencia momento a momento con el individuo, en la misma velocidad en la que fluye el tiempo, y que forma una multiplicidad ilimitada de relaciones, únicas de persona a persona y de momento a momento.

Rhythm expresses something different from thought. The meaning of both is incommensurable. Rhythm cannot be explained completely by thought nor can thought be put in terms of rhythm, or converted or reproduced. They both find their connection and identity in common and universal human life, the life principle, from which they spring and upon which they can build further (Richter 1926, 21)

\section{De las abstracciones fílmicas a las abstracciones del código}

El nacimiento del cine abstracto a inicios del siglo veinte contiene algunas de las claves para entender el proyecto Ritmo 2021. De forma más precisa, referentes tales como Lichstspiel Opus 1 (1921), Symphonie Diagonale (1925) o el ya referido Rhythmus 21 (1921) permiten establecer un vínculo conceptual y estético entre dos medios distintos, el celuloide y el código de programación. Se enfoca en los elementos rectores de la propuesta, como la abstracción, el ritmo y la materialidad. Estos tres filmes son considerados pioneros del cine abstracto por proponer una evolución de la pintura abstracta (los tres autores eran artistas visuales) hacia lo que ellos denominaban pintar con el tiempo (Malerei mit Zeit), con lo que exploraban, mediante sus experimentos fílmicos, la relación entre formas (abstractas) y el tiempo (Schwierin y Naumann $2015,19)$. Así mismo, estas formas abstractas estaban fuertemente ligadas al ritmo, el cual se plasmaba ya sea en el ritmo visual entre las formas, en los casos en que la película fuera silente, o directamente con la música cuando la proyección requería un acompañamiento musical simultáneo (Schwierin y Naumann 2015, 19). En el caso específico de Rhythmus 21, esta carecía de sonido y el ritmo denotaba la "orquestación" de figuras geométricas como cuadrados, rectángulos y líneas sobre fondos blancos o negros (Naumann 2015); es decir, enfatizando el movimiento y su ritmo asociado. Por último, la materialidad se expresa en la forma en que estas piezas implicaban pintar directamente sobre el celuloide, de una forma en que el instrumento y el tema estaban mezclados (Leyokki 2020, 304). Esto puede interpretarse como una forma de resolver la falta de una realidad mediada y su representación.

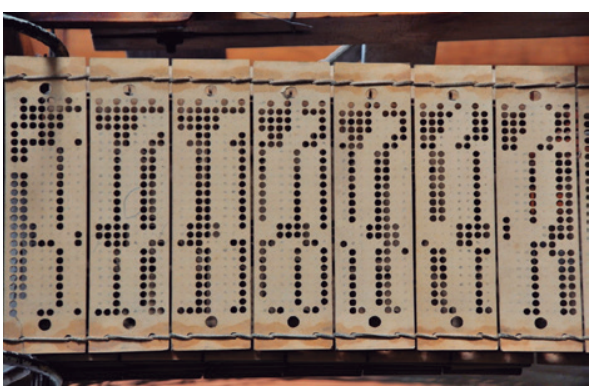

Figura 1 - Telar de Jacquard (detalle perforaciones)

Para entender mejor esta conexión entre dispositivos de imagen (como el celuloide de las películas abstractas) y los dispositivos de cálculo (como el computador como máquina de imágenes), y su relación con la abstracción, el ritmo y la materialidad, dos ejemplos canónicos pueden ser útiles. El primero es el famoso telar de Jacqard de inicios del siglo xix, el cual producía imágenes bordadas a partir de patrones codificados en una tarjeta perforada (Manovich 2001, 22) (figura 1). El segundo es el computador Z3 (1941) construido por el alemán Konrad Zuse, el cual fue uno de los primeros computadores digitales binarios y que se destacó por usar un celuloide de una película para codificar sus instrucciones en perforaciones (Manovich 2001, 25) (figura 2). Debe verse cómo ambos dispositivos empleaban las perforaciones sobre un soporte material como representación abstracta de imágenes en el caso del telar, y de instrucciones y datos en el caso del computador Z3. Es más, la abstracción en el último caso es tal que, por un lado, las perforaciones correspondían a su vez otra abstracción, como las instrucciones de máquina y, por el otro lado, el carácter de símbolo concreto del celuloide (las posibles escenas retratadas en cada fotograma) perdían su valor completamente en favor del símbolo abstracto a ser procesado. La materialidad 
ya señalada en los soportes se hacía más patente al incluir todo el aparataje mecánico requerido para mover dicho soporte y leer las instrucciones perforadas de una manera secuencial. Esta última observación no solo apunta a un ritmo de procesamiento de instrucciones en este caso, sino también a que dicho procesamiento es serial.

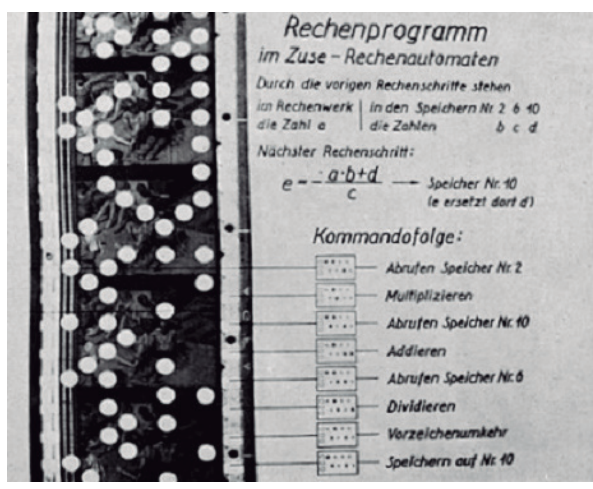

Figura 2 - Celuloide con instrucciones perforadas de computador Z4

Ya en esta etapa podemos considerar al híbrido moderno de hardware y software como una máquina de medios donde los cálculos numéricos pueden generar imágenes y sonidos. En este arreglo técnico, los lenguajes de programación son la abstracción por excelencia que permite esta flexibilidad de representación. Debe verse que, si como se citó anteriormente, el lenguaje es un proceso de creación libre, esto también se aplica a un lenguaje de programación. Propiamente, la abstracción del código de los lenguajes de programación consiste en una serie de capas que van desde los lenguajes de alto nivel, más entendibles por humanos, a lenguaje de máquina e incluso niveles de voltaje en los procesadores que, al final, ejecutan todas las tareas. Esto último es una confirmación de que la abstracción y los símbolos no son opuestos a la materialidad ya que "códigos operacionales elementales [...] se reducen a manipulaciones de signos absolutamente locales y de este modo (para decirlo con Lacan) a significantes con potenciales eléctricos" (Kittler 2017, 42). Estos símbolos abstractos serían universales, a su vez, dada la estandarización de los sistemas de cómputo y de los lenguajes de programación. Así, abstracción, símbolos universales y materialidad estarian presentes en el ecosistema mediático facilitado por el software. El ritmo y la serialidad estarian dados, entonces, por la frecuencia y la respectiva velocidad de procesamiento de las instrucciones simbólicas en el hardware de un computador. A pesar de metáforas y simulaciones, como la multitarea, estas instrucciones aún se procesan de manera serial, al igual que el cinematógrafo proyectaba fotogramas de uno a uno.

\section{Caso de estudio: Ritmo 2021 como programación estética}

La idea inicial de desarrollar un corto abstracto experimental con lenguajes de programación obedece a la certeza, enunciada hace más de cincuenta años, de que "the digital computer opens vast new realms of possible aesthetic investigation" (Youngblood 2020, 189). También a observaciones, como la del artista Mark Napier, las cuales dicen que "el diseño de software tiene un carácter muy escultórico" (Tribe y Jana 2006, 10). No obstante, la idea no es nueva, así lo muestran experiencias como la producción de una animación usando un computador en 1968 (Youngblood 2020, 185) o trabajos pioneros en la animación usando secuencias de programación (aunque aún usando tecnologías fílmicas) como el conocido (Pixillation 1970). Sin embargo, el objetivo de la propuesta reposa en la actualización usando nuevas tecnologías y en el enriquecimiento pedagógico del ejercicio. Así, puede decirse que el esfuerzo se inscribe dentro de lo que se conoce como "programación estética" que permite reflexionar sobre la cultura actual a través de la programación creativa (Soon y Cox 2020, 14).

Partiendo de ese marco de referencia, el proyecto inició a finales de 2020. El lenguaje de programación Processing fue seleccionado por su sencillez y por ser una herramienta bastante extendida en el campo de las artes. Las primeras decisiones de diseño respondían a la pregunta ¿qué elementos audiovisuales, que no eran posibles en Rhythmus 21 , podrían incorporarse? La respuesta fueron los siguientes requerimientos: uso del color, figuras abstractas en tercera dimensión, sonido sincronizado y escenas aleatorias. El trabajo de programación se está llevando a cabo bajo un modelo iterativo, con revisiones semanales entre los dos programadores (que a su vez son los autores de este texto). No hubo un diseño previo preparado y, a manera de experimentación artística, se privilegiaba un método de ensayo y error, y de ir produciendo la pieza sin planeación. Este aspecto coincide con palabras como las de Joh F. Simon Jr. citado en (Tribe y Jana 2006, 25):

Yo enfoco la programación como si fuera escritura creativa. No empiezo con un diagrama de flujo. Empiezo con un bucle simple y luego observo cómo afectan los pequeños cambios en el código al resultado visual. Nunca planifico qué hará el código exactamente, y a menudo acabo incorporando algo que no había anticipado pero que el código ha hecho durante las pruebas.

Durante la ejecución de las iteraciones surgieron los siguientes problemas. Debe verse que la ventaja del método seguido de investigación-creación es su flexibilidad. El no tener una planeación rígida desde el inicio permitió tomar decisiones basadas en los problemas con resultados estéticos inesperados. El primer problema ha sido el sonido (música). Se tenía pensado dejar la parte visual en Processing y usar un lenguaje especializado como SuperCollider para la parte sonora, con el fin de efectuar la conexión entre los 
dos programas. Sin embargo, esto traía la complejidad adicional de la sincronización y de disparar eventos sonoros de una manera externa al flujo visual logrado. Por ello se decidió realizar el sonido también en Processing usando la biblioteca "Sound". El segundo problema fue consecuencia del requerimiento de aleatoriedad, lo cual demandaba que las distintas escenas del corto se intercalaran de forma fortuita sin orden aparente, e incluso con duraciones diferentes para nuevas apariciones de la misma escena. Aunque esto es posible gracias a la programación, justo uno de los conceptos rectores de toda la propuesta, el resultado se asemejaba más a un collage visual con flujos audiovisuales con interrupciones, lo cual es todo lo contrario a la premisa del ritmo. Desde el punto de vista de la estructura modular del programa, la complejidad creciente sugería el uso de abstracciones propias de la programación orientada a objetos como las clases abstractas. Generalmente, los cursos de Processing enfatizan un solo bucle para una escena visual y no la organización de múltiples escenas, por lo que estas características, más modulares avanzadas que visuales, permitieron mejorar el orden y legibilidad del código. Una vez superados estos inconvenientes, se produjo un prototipo ${ }^{1}$ en el cual todo lo visual se produjo con código, añadiendo después el sonido de manera convencional en un editor de video ${ }^{2}$ (figura 3 ).

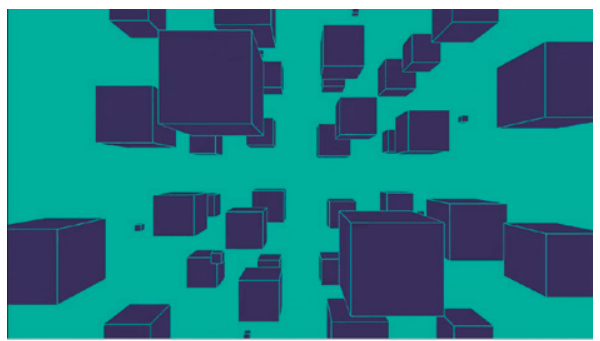

Figura 3 - Fotograma de prototipo Ritmo 2021

\section{Conclusiones y trabajo futuro}

Como todo proyecto de investigación-creación, el resultado principal es una pieza u obra que provoque una experiencia sensitiva a través del uso del lenguaje estético. Dado que Ritmo 2021 depende de la imagen en movimiento, promueve las formas de apreciación dinámicas donde el ritmo, en este caso audiovisual, es el vector comunicativo. Sin embargo, esta cualidad no se circunscribe solo al mensaje, sino que va más allá para acudir a los símbolos abstractos contenidos en un lenguaje, sea este estético, y medie entre artista y espectador, o un lenguaje de programación que medie entre artista, máquina y espectador. De esta forma, las abstracciones y sus distintas capas crean interfaces de goce estético a través del ritmo, la variación y la secuencia de estímulos audiovisuales. Así, el prototipo logrado de Ritmo 2021 acude a estrategias similares que las películas abstractas pioneras, pero actualizando el soporte de inscripción (medio) de celuloide a lenguajes de programación. Sin embargo, de ello no debe inferirse que todo el ejercicio implica un acto de imitación, acaso nostálgica, sobre una vanguardia ya centenaria. Por el contrario, el proyecto corresponde más bien a un détournement sobre la relación entre abstracciones numéricas y de imágenes. De esta forma, y como en un bucle de programación, se completa un giro crítico: si una de las primeras computadoras usaba abstracciones sobre un soporte de imágenes en movimiento para realizar cálculos, Ritmo 2021 sería un ejemplo de abstracciones sobre un soporte de cálculo (lenguaje de programación) para obtener imágenes en movimiento.

Desde un punto de vista más teórico, puede decirse que Ritmo 2021 permite enlazar varios conceptos importantes. Respecto a una de las afirmaciones del párrafo anterior, lo que ocurre en este tránsito de soportes y medios es más una "remediación" (Hayles 2002 , 5), posibilitada por el computador como objeto material-semiótico (Hayles 2002, 15). Este proceso es el que permite al computador, como máquina de medios, crear tres tipos de abstracciones que, a su vez, crean la obra: la abstracción del lenguaje (de programación) que controla el computador, la abstracción de superestructuras en las que se organizan las líneas de código de un lenguaje de programación (clases en programación orientada a objetos), y la abstracción visual que finalmente es contemplada por el espectador y que se visualiza como una película abstracta. Debe aclararse que la obra no reposa en la última abstracción, es decir, en la visual. La obra en realidad está compuesta por la interacción de las tres abstracciones que no pueden ser pensadas la una de la otra, y se infiere también del acto de programar como un acto eminentemente estético.

Finalmente, debe resaltarse varias cualidades del enfoque del proyecto. El uso de software libre en lenguajes de programación apunta tanto a una soberanía tecnológica como estética. El mismo soporte del audiovisual producido como líneas de código inmediatamente abre la posibilidad para la colaboración e intervención de la pieza, siempre y cuando se tenga acceso a dicho código, como es el postulado del software libre. En este sentido, a la obra se le adicionaría la abstracción de las redes que permitirían de cierta forma cumplir aquello de ser una escultura social, donde el espectador no solamente experimente el acto artístico de forma pasiva, sino que pueda participar. Solo tendría que descargar, modificar y compartir el código de Ritmo 2021. Esto permite visualizar cual sería el trabajo futuro: culminar el corto como está pensado, refinando la parte visual y produciendo el sonido con líneas de programación integradas y sincronizadas a lo visual. Más interesante aún es la perspectiva de especulaciones que pueden poblar ese trabajo futuro y que se materializarían en nuevas formas de creación y distribución de contenidos audiovisuales. En tiempos donde nuestros cuerpos también han sido sometidos a la abstracción de la videoconferencia, la promesa de la creación colectiva constituye esa esperanza de lo estético como algo reconfortante y sublime. 


\section{Agradecimientos}

Este artículo es un producto del proyecto llamado Ritmo 2021: producción de un corto audiovisual experimental usando técnicas de programación, el cual es beneficiario de la Convocatoria para la financiación de proyectos de Investigación-Creación de la Facultad de Artes - 2020, de la Facultad de Artes de la Universidad Nacional de Colombia, Sede Bogotá. El proyecto es desarrollado por el grupo de investigación-creación </ espam> "Espacio de producción abierta de medios", perteneciente a la Escuela de Cine y Televisión de la Universidad Nacional de Colombia. Los autores agradecen a la Escuela y a la Vicedecanatura de Investigación de la Facultad de Artes.

\section{Notas finales}

${ }^{1}$ Se privilegió en uso de la palabra "prototipo", como se usa en los proyectos de software, a la de "corte" del ámbito audiovisual. Esto se ajusta más a la naturaleza del proyecto y abre nuevas posibilidades sobre cómo entender una pieza audiovisual inmersa en la cultura del software.

${ }^{2}$ El primer prototipo funcional completo fue presentado también a la convocatoria de Avanca Cinema en la categoría "Video". Esta acción busca recoger sugerencias que puedan retroalimentar el proceso y conducir a una versión final que se acerque a los objetivos.

\section{Bibliografia}

Chomsky, Noam. 2008. The Essential Chomsky: Nueva York: The New Press.

Einstein, Albert. "Albert Einstein on space-time." Encyclopedia Britannica, 2016.https://n9.cl/o02tx Accedido el 3 de marzo 2021https://n9.cl/o02tx.

Hayles, N. Katherine. 2002. Writing Machines. Cambridge: MIT Press.

Heidegger, Martin. 2003. El concepto del tiempo. Madrid: Editorial Trotta S. A.

Kittler, Friedrich. 2017. "No hay Software". En No hay software y otros ensayos sobre filosofía de la tecnología (Ed. Alejandro Duque y Andrés Burbano), 39-46. Manizales: Editorial Universidad de Caldas.

Leyokki. 2020. "Making a motion score: a graphical and genealogical inquiry into a multi-screen cinegraphy". En Sound \&Image. Aesthetics and Practices (Ed. Andrew Knight-Hill), 294-315. Abingdon y Nueva York: Routledge.

Lévy, Pierre. 1999. ¿Qué es lo virtual? Traducido del francés por Diego Levis: Barcelona, Paidós.

Machado, Arlindo. 2007. "El imaginario numérico: simulación y síntesis." En El medio es el diseño audiovisual, (Ed. Jorge LaFerla), 101-109. Manizales: Editorial Universidad de Caldas.

Manovich, Lev. 2001. The Language of New Media. Cambridge: MIT Press.

Minkowski, Hermann. 1976. "The Union of Space and Time." En The Concepts of Space and Time. Their Structure and Their Development, (Ed. M. Capek), 339351. Dordrecht: Springer-Dordrecht.

Montfort, Nick. 2016. Exploratory Programming for the Arts and Humanities. Cambridge: MIT Press.

Naumann, Sandra. 2015. "The Expanded Image: On the Musicalization of the Visual Arts in the Twentieth Century". En Audiovisiology. A reader, (Eds. D. Daniels y
S. Naumann), 504-525. Colonia: Verlag der Buchhandlung Walther König.

Richter, Hans. 1952. "Easel Scroll Film". En Magazine of Art N. ${ }^{\circ} 45:$ 78-86.

Richter, Hans. 1926. "Rhythm", Little Review (Winter 1926), 21.

Schwierin, Marcel y Naumann, Sandra. 2015. "The Musicality of Abstract Film". En Audiovisiology. A reader, (Eds. D. Daniels y S. Naumann), 19-23. Colonia: Verlag der Buchhandlung Walther König.

Soon, Winnie y Cox, Geoff. 2020. Aesthetic Programming. A Handbook of Software Studies. Londres: Open Humanities Press.

Tribe, Mark y Jana, Reena. 2006. Arte y nuevas tecnologías. Colonia: Taschen.

Youngblood, Gene. 2020 (1970). Expanded Cinema. $50^{\text {th }}$ Anniversary Edition. Nueva York: Fordham University Press.

\section{Filmografia}

Lichtspiel Opus 1. 1921. De Walter Ruttmann. Alemania. https://www.youtube.com/watch?v=aHZdDmYF ZN0\& $\mathrm{t}=53 \mathrm{~s}$ Accedido 3 de marzo de 2021.

Pixillation. 1970. De Lillian Schwartz. Estados Unidos. https://vimeo.com/56480534 : Accedido 3 de marzo de 2021.

Rhythmus 21. 1921. De Hans Richter. Alemania. https:// www.youtube.com/watch?v=239pHUy0FGc : Accedido 3 de marzo de 2021.

Symphonie Diagonale. 1925. De Viking Eggeling. Alemania. https://www.youtube.com/watch?v=MtBjFv46XL Q : Accedido 3 de marzo 2021. 